\title{
Applied Multiregional Demography: Migration and Population Redistribution
}

\author{
by Andrei Rogers \\ Dordrecht, Heidelberg, London, New York: Springer 2016 \\ ISBN 978-3-319-22317-9 \\ Softcover $\$ 54.99,114$ pp.
}

\author{
Reviewed by David A. Swanson \\ Department of Sociology, University of California Riverside
}

As I read through Applied Multiregional Demography: Migration and Population Redistribution, I repeatedly stopped to compare it to a book I read by Frans Willekens: Multistate Analysis of Life Histories with R (for a review, see Swanson 2015). I find Willekens' book much more innovative and useful than this book by Rogers.

Willekens' book is much more innovative because he discusses the data problems faced when considering multi-state demography, and he offers ways to overcome them (e.g., with micro-level data). Rogers however, focuses on the use of aggregated data and gives the problems associated with aggregated data very short shrift. Instead, he spends too much of the book complaining about the shortcomings of other approaches. Rogers also spends too much of the book on another complaint - the use of "net migration" as a concept in demographic analysis. I find his complaint ironic given that in this book, there are 26 instances of the use of "natural increase," which is itself a net measure, conceptually the same as net migration. Unlike "Requiem for the net migrant" (Rogers 1990), I have never run across a work by Rogers titled "Requiem for the natural increment."

I find the discussion of another construct also to be ironic. Toward the end of the book, Rogers notes that "double-entry bookkeeping" is conceptually similar to "multi-regional migration." Of course it is! But what Rogers fails to bring into this discussion is the fact that for all businesses, including those who use double-entry bookkeeping and those that do not, the bottom line is "profit," a measure that is conceptually the same as net migration. As is the case with the "natural increment," I have never read something by Rogers entitled "Requiem for profit."

The actual examples of applications provided by Rogers in terms of multi-regional demography all involve large pieces of geography. There is nothing on small pieces of geography, such as counties, much less census tracts. Is this because of the difficulty encountered in getting the data needed to implement the multi-regional approach for small areas such as counties, census tracts, and the like? Even for the examples he provides, there is absolutely no mention of the issues affecting the validity and reliability of the data required. This is especially important in the US, where the problematic "long form" data needed to use a multi-regional perspective in the past have been replaced by the far more problematic "American Community Survey" data. As such, I find the examples to be not very useful.

For what it does cover-large geographic areas, aggregate data, and a list of the problematic issues associated with net migration - the book is fine. However, if you are not interested in polemics on net migration, but are interested in actually implementing the multi-regional approach, especially for small geographic levels using micro-level data, I recommend instead the book by Willekens, who provides a much more innovative perspective, along with useful examples. In a similar vein, another useful example is found in the work of Wilson (forthcoming), who uses the "multi-regional" perspective to effect dynamic changes in ethnic identity in a micro-simulation projection. 


\section{References}

Rogers, A. 1990. Requiem for the net migrant. Geographical Analysis 22:283-300.

Swanson, D.A. 2015. Review of Multistate Analysis of Life Histories with R, by Frans Willekens. Canadian Studies in Population 42(3-4):80-81.

Wilson, T. nd. The future of Australia's indigenous population. Population Studies. Forthcoming. 